\title{
APLICAÇÃO DE FERRAMENTAS DE GERENCIAMENTO NOS LABORATÓRIOS DA ÁREA DE FABRICAÇÃO DA UFV
}

\section{MANAGEMENT TOOLS APPLICATION IN THE UFV MANUFACTURING LABS}

\section{BENINI ${ }^{1, *}$ e L. M. CARVALHO ${ }^{1}$}

${ }^{1}$ Universidade Federal de Viçosa, Departamento de Engenharia de Produção e Mecânica, Viçosa, Minas Gerais, Brasil

${ }^{*}$ Corresponding author. Universidade Federal de Viçosa, Departamento de Engenharia de Produção e Mecânica, Viçosa, Minas Gerais, Brasil, Phone: +55 31 36126500

Endereço de e-mail: lucasbenini@gmail.com (L.Benini).

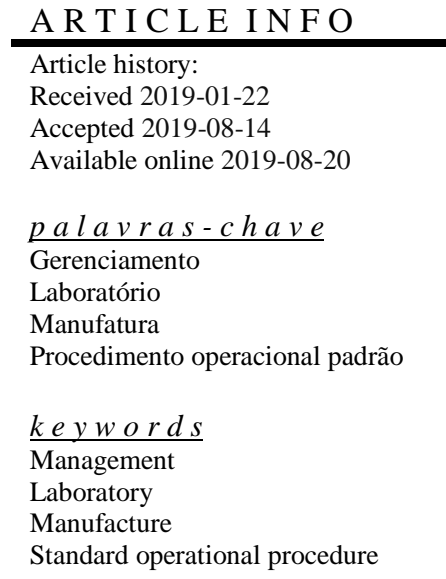

\begin{abstract}
R E S U M O
Este trabalho aborda o gerenciamento dos Laboratórios de Manufatura Assistida por Computador, de Manufatura e de Usinagem do Departamento de Engenharia de Produção e Mecânica $(D E P)$ da Universidade Federal de Viçosa (UFV). O objetivo deste trabalho é elaborar um plano de gerenciamento para três laboratórios da área de fabricação do DEP que contempla procedimentos operacionais padrões, procedimentos analíticos e estudo de arranjo físico. A originalidade deste trabalho está relacionada à utilização e adaptação de metodologias e ferramentas gerenciais para que os laboratórios possam realizar suas atividades de maneira padronizada, minimizando a perda de conhecimento no tempo e baseada em conceitos prestigiados na gestão moderna de organizações. Por meio de entrevistas estruturadas foi obtido o insumo para a identificação, mapeamento $e$ procedimento dos processos usinagem por fresamento e por torneamento. Os resultados alcançados permitem um gerenciamento dos materiais permanentes e consumíveis destes laboratórios mais eficiente.
\end{abstract}

A B S T R A C T

The present article deals the management of the Computer Aided Manufacturing, Manufacturing and Machining Laboratories of the Department of Production and Mechanical Engineering (DEP) of the Federal University of Viçosa (UFV). The aim of this work is to elaborate a management plan for three laboratories of the DEP manufacturing area that includes standard operating procedures, analytical procedures and layout study. The originality of this work is related to the use and adaptation of methodologies and management tools so that the laboratories can perform their activities in a standardized way, minimizing knowledge loss along the time and based on prestigious concepts in the modern management of organizations. Through structured interviews, the input for the identification, mapping and procedure of milling and turning processes was obtained. The results achieved allow management of the permanent materials and consumables of these laboratories more efficient. 


\section{INTRODUÇÃO}

Um experimento, entre outras definições, trata-se de um "ensaio científico destinado à verificação de um fenômeno físico" (Ferreira, 2009). Hoje, a experimentação é massiva nos laboratórios de ensino e pesquisa. Com ela, o estudante é capaz de associar conceitos teóricos com a ocorrência real do fenômeno, além da compreensão mais panorâmica dos conceitos apresentados (Lima e Garcia, 2011), bem como o pesquisador pode testar hipóteses. No entanto, são precisos materiais, equipamentos e recursos humanos para que haja a plena consecução do objetivo dos laboratórios, de forma que se os profissionais não estiverem habilitados para o trabalho demandado ou os demais recursos não forem adequados, o objetivo não será alcançado (Ferreira e Gomes, 1995).

Além disso, processos de usinagem, principais tarefas de ensino e pesquisa desenvolvidas no Laboratório de Manufatura (Lab-MAN) do Departamento de Engenharia de Produção e Mecânica da UFV (DEP), são estrategicamente importantes, visto que há cada vez mais investimento em novas tecnologias para a melhoria desses processos. Um problema corriqueiro decorrente do avanço tecnológico nesta área foi o de gestão de estoque, uma vez que houve um grande incremento em novas ferramentas e ferramental de apoio, gerando uma quantidade massiva de informações a serem controladas (Zonta Junior et al., 2008).

Quanto ao Lab-MAN, este era alocado junto ao Departamento de Engenharia Florestal (DEF) da UFV até 2017 devido à falta de espaço físico do $\mathrm{DEP}$ e, contudo, tinha equipamentos e consumíveis alocados em vários espaços. Isto dificultava o gerenciamento dos equipamentos e a manutenção dos mesmos, bem como o controle de estoque de material consumível e assim, o laboratório indispunha de um plano de gerenciamento de suas atividades. Em virtude da natureza dos processos de usinagem e da necessidade do laboratório atingir seu objetivo primário, a boa prática em gestão era emergente ao laboratório. Com a ampliação do DEP, o Lab-MAN foi contemplado com uma área de $85 \mathrm{~m}^{2}$. Assim, foi possível tornar este espaço dedicado e viabilizou-se, portanto, a alocação de todos os equipamentos e consumíveis em um único lugar e passível de ser bem gerenciado.

Elaborar o plano de gerenciamento dos Laboratórios de Manufatura, de CAM e de Usinagem do Departamento do DEPUFV é o principal objetivo deste projeto. São objetivos específicos:

- Elaborar o inventário e procedimentos de controle de estoque de materiais consumíveis;

- Estudar o leiaute do Lab-MAN;

- Formatar e redigir o manual de procedimentos analíticos dos laboratórios;

- Elaborar o plano de tarefas prioritárias e estabelecer procedimentos operacionais padrão (POP) para as aulas práticas das disciplinas de fabricação.

\section{GERENCIAMENTO DE LABORATÓRIOS}

Conforme Silva (2015), a Administração Pública é responsável pela decisão e implementação de ações necessárias para a gestão daquilo que é público. É preciso que ela busque constantemente, assim como a iniciativa privada, a melhoria contínua de seus processos e produtos, e, portanto, sua própria evolução, que se pauta justamente no "aperfeiçoamento dos serviços prestados pelo Estado à população”. Meirelles (2004) conceitua o serviço público como aquilo cuja função é satisfazer necessidades da coletividade ou do Estado e é prestado pela própria Administração Pública. Deming (1990) ressalta que "O setor público deve buscar e aplicar as técnicas adequadas de administração privada para aperfeiçoar suas análises e avaliação de resultados".

Assim, para que os laboratórios que são objeto de estudo nesta pesquisa e elementos constituintes de uma instituição pública atendam a seu público de maneira eficiente, também se faz necessário esta estratégia. Os conceitos, técnicas e metodologias empregados na pesquisa que serviram de base para o aperfeiçoamento das práticas internas dos laboratórios serão abordados conceitualmente nos próximos tópicos.

\subsection{Qualidade}

Para se compreender a gestão da qualidade na administração pública, deve-se primeiramente definir o que se trata de qualidade. Campos (1992) afirma que "um produto ou serviço de qualidade é aquele que atende perfeitamente, de forma confiável, de forma acessível, de forma segura e no tempo certo às necessidades do cliente". Segundo Juran (1992) apud Kohl e Oliveira (2012), "a qualidade é adequação ao uso, que resulta da combinação de um produto (bem ou serviço) das características que respondem as necessidades dos clientes e ausência de deficiências". A busca pela qualidade, no ponto de vista mercadológico, teve vários momentos na história e tendências. Com a Segunda Guerra Mundial, o controle de qualidade foi amplamente utilizado nas indústrias americanas, de forma que a demanda por suprimentos militares era foi atendida com qualidade, na quantidade necessária e mais barato (Werkema, 1995).

O crescente interesse pela qualidade na iniciativa privada ao longo do tempo justifica-se pela vantagem competitiva que ela oferece. Já no setor público, a busca pela qualidade orientase para que as instituições públicas atendam a expectativa, ou seja, a provisão de bens e serviços dos quais a sociedade ou segmento interessado necessitam (Kohl e Oliveira, 2012). Segundo Campos (1992), na qualidade total, o gerenciamento da rotina fundamenta-se na padronização. O gerenciamento da rotina trata-se da busca melhorar o desempenho das pessoas de uma organização em suas funções operacionais para que as pessoas executem da melhor maneira possível (Campos, 1994). Como está diretamente relacionado com gerenciamento da rotina e faz uso da padronização, o próximo tópico desta revisão de literatura abordará este tema de maneira mais ampla.

\subsection{Padronização}

Conforme Campos (1992), “a padronização é considerada a mais fundamental das ferramentas gerenciais", pois é um meio para atingimento de melhores resultados. Tal fato é explicado pelo seu objetivo de redução de variabilidade dos processos, isto é, "os produtos devem atender às expectativas dos consumidores de forma regular”. É importante salientar ainda que a padronização não se limita ao registro da prática, inclui também sua utilização, isto é, o treinamento e verificação de que a prática executada está conforme com a registrada. Campos (1992) afirma também que "só é possível manter o domínio tecnológico de um sistema mediante a padronização". O conceito de domínio tecnológico envolve a 
capacidade de estabelecer processos e da organização assegurarse de que a prática executada segue a padronizada.

\subsection{Arranjo Físico}

Segundo Slack et al. (2009) "o arranjo físico de uma operação ou processo é como seus recursos transformadores são posicionados uns em relação aos outros e como as várias tarefas da operação serão alocadas a esses recursos transformadores. Juntas, essas duas decisões irão ditar o padrão do fluxo dos recursos transformados à medida que eles progridem pela operação ou processo". Há vários benefícios provenientes de um dimensionamento de arranjo físico adequado. Entre eles, segundo Peinado e Graeml (2007), há a melhoria do ambiente de trabalho por meio da melhoria nas condições ergonômicas do trabalho.

\subsection{Administração de materiais}

Chiavenato (2005) conceitua a administração de materiais como "ter os materiais necessários na quantidade certa, no local certo e no tempo certo à disposição dos órgãos que compõem o processo produtivo da empresa". Isto é importante devido aos investimentos financeiros necessários em materiais. Uma boa administração de materiais procura manter o mínimo de capital investido e de tempo em estoque sem prejudicar o processo produtivo. Ainda segundo Chiavenato (2005), estoque é o acúmulo desde matéria-prima a produtos acabados "que não é utilizada em determinado momento na empresa, mas que precisa existir em função de futuras necessidades". Assim, é preciso sempre buscar a compensação entre os custos e benefícios de manter um determinado nível de estoque.

\section{METODOLOGIA}

A pesquisa foi realizada no Prédio dos Laboratórios das Engenharias da UFV (LABENGE), contemplando 3 laboratórios: Lab-MAN, Laboratório de Manufatura Assistida por Computador CAM (Lab-CAM) e Laboratório de Usinagem (Lab-USI) que são vinculados ao DEP. No processo de realização da pesquisa foi utilizado usado o método qualitativo. Entrevistas com integrantes do laboratório foram conduzidas para o entendimento dos procedimentos dos laboratórios e dados secundários foram utilizados no estudo. Foi feita, a priori, uma revisão bibliográfica, no intuito de compreender a literatura que é de interesse da pesquisa, bem como para a escolha fundamentada das metodologias utilizadas. Posteriormente, foram definidos softwares que seriam necessários para dar suporte à realização da pesquisa. Os softwares utilizados e o objetivo podem ser verificados na Tabela 1.

Após a definição dos recursos necessários, foi feita a busca da parte documental que baseou posterior análise, tais como normas regulamentadoras, manuais e programas analíticos das disciplinas ministradas no DEP. Foram elencados possíveis temas e a literatura que os abarcavam que continham informações que poderiam ser relevantes para o estudo.

Tabela 1 - Relação entre software/ferramenta e objetivo da utilização.

\begin{tabular}{l|l} 
Software/ferramenta & \multicolumn{1}{c}{ Objetivo } \\
\hline Bizagi Modeler $^{\odot}$ & Elaboração dos fluxogramas \\
\hline Autocad & $\begin{array}{l}\text { Representação gráfica do modelo } \\
\text { do laboratório de manufatura }\end{array}$ \\
\hline Lucidchat.com $^{\odot}$ & Elaboração do organograma \\
\hline Microsoft Excel $^{\odot}$ & Elaboração de planilhas eletrônicas \\
\hline
\end{tabular}

Foram conduzidas entrevistas com os técnicos do laboratório para estimar-se, baseado em dados históricos, a necessidade de materiais e ferramentas em períodos futuros quanto ao inventário e previsão de demanda do Lab-MAN. No Lab-CAM, os principais recursos são de tecnologia da informação. Portanto, foram elencados quais são os equipamentos utilizados. Paralelamente, foi feita uma busca por políticas e normas de outras instituições públicas para respaldar a compra de novos equipamentos buscando-se os pontos relevantes e aplicáveis ou não no contexto do laboratório. Quanto ao estudo de arranjo físico do Lab-MAN, a pesquisa aplicou o método de levantamento de área física para cada centro de trabalho do Centro de Usinagem Comandado Numericamente (CNC) e do torno convencional. O método é exibido na Tabela. 2. Também foram feitas comparações pontuais entre recomendações em literatura e a situação atual do laboratório.

Tabela 2 - Conceitos para uso do método de levantamento da necessidade da área física (adaptado de Peinado e Graeml, 2007).

\begin{tabular}{l|l}
\multicolumn{1}{c|}{ Conceito } & \multicolumn{1}{c}{ Definição } \\
\hline Aresta viva & Lado do equipamento no qual é realizado operações produtivas. \\
\hline Superfície projetada (Sp) & Projeção ortogonal do equipamento no chão. \\
\hline Superfície de operação (So) & $\begin{array}{l}\text { Área requerida para que o operador realize sua atividade segura e eficientemente. Cálculo: So } \\
=\text { (dimensão da aresta viva)*(dimensão da aresta não viva/2) e ainda considera-se uma faixa } \\
\text { mínima para efeitos de cálculo para a dimensão da aresta não viva de no mínimo 0,5 m quando } \\
\text { a dimensão da aresta não viva é muito pequena e no máximo 2,0 m quando a dimensão da aresta } \\
\text { não viva é muito grande. }\end{array}$ \\
\hline Superfície de circulação (Sc) & $\begin{array}{l}\text { Área requerida para fluxo de pessoas e materiais envolvidas no processo produtivo. Cálculo: Sc } \\
\text { = (Sp + So)/2 desde que a dimensão diferente da aresta viva desta superfície não supere } 3 \text { m. }\end{array}$ \\
\hline Corredor de passagem & $\begin{array}{l}\text { Área destinada ao fluxo de pessoas e materiais não diretamente envolvidas no processo } \\
\text { produtivo. Deve ter no mínimo 0,6 m. }\end{array}$ \\
\hline
\end{tabular}

Como os conceitos apresentados na Tabela 2 são relativos ao planejamento de centros de trabalho industriais, a pesquisa adaptou os conceitos de superfície de circulação e corredor de passagem para aplicá-los no Lab-MAN. Os demais conceitos foram utilizados conforme descritos na literatura. A adaptação correspondente é apresentada na Tabela 3. A Figura 1 apresenta esquematicamente o desdobramento do objetivo e a metodologia deste trabalho. 
Tabela 3 - Adaptação dos conceitos apresentados na Tabela

\section{2 para contextualização no laboratório.} Conceito Adaptação

Superfície de circulação (Sc) Corredor de passagem
Área necessária ao fluxo de materiais e observação dos alunos.

Área correspondente à circulação livre e de maior fluxo dos alunos.
Objetivo principal: Elaborar o plano de gerenciamento do Laboratório de Manufatura do Departamento de Engenharia de Produção e Mecânica (DEP) da UFV

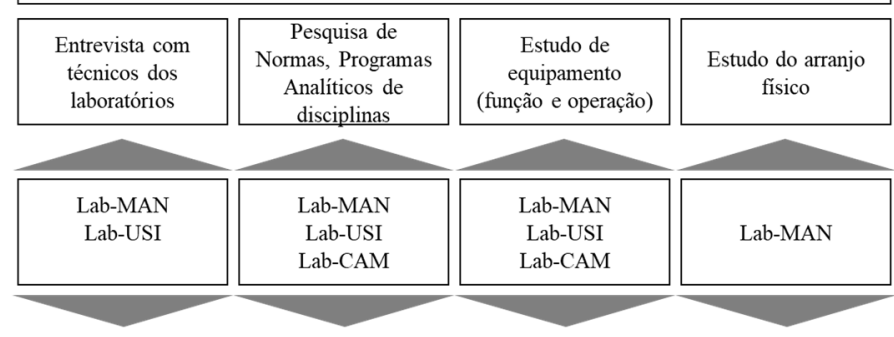

Elaboração e formatação dos principais procedimentos operacionais e analíticos da Área de Fabricação do DEP

Figura 1 - Objetivo e metodologia.

\section{RESULTADOS}

Foi elaborado um manual contendo a proposição de normas para os três laboratórios e os procedimentos operacionais padrão. Conforme Campos (1994), somente aquilo que é necessário para garantir o resultado desejado deve ser padronizado. Assim, foram elencados os procedimentos relativos ao uso para fins de ensino, pesquisa e extensão.

\subsection{Procedimentos operacionais padrão (POP's)}

Laboratório de CAM: o Lab-CAM, cujo objetivo é "Auxiliar e dar suporte aos usuários desenvolvimento de projetos e trabalhos acadêmicos através de modelagem e simulação de sistemas em 3D e de processos de manufatura, contribuindo para com o processo de ensino, pesquisa e/ou extensão", é bem distinto dos objetivos dos Lab-MAN e LabUSI, ambos relacionados a Usinage. Em virtude da natureza das atividades do Lab-CAM ser diferente dos demais laboratórios, foi elaborado um manual exclusivo para o Lab-CAM. A Figura 2 apresenta o sumário do manual.

Ele contém o objetivo, área de conhecimento, horário de funcionamento, caracterização do laboratório e dos usuários, normas, relação de patrimônios, um procedimento operacional padrão e Política de Compra de Equipamentos. Além disso, foi elaborado com base no trabalho de Lima (2014). O Lab-CAM possui atualmente os seguintes softwares: Ansys ${ }^{\circledR}$, Adams Car ${ }^{\circledR}$, Solid Works ${ }^{\circledR}$, Matlab ${ }^{\circledR}$, Catia ${ }^{\circledR}$, Inventor $\AA$ e atende 12 disciplinas dos cursos de Engenharia de Produção e Mecânica da UFV (MEC 191 Comunicação Gráfica e Tecnologia Mecânica, MEC 241 Laboratório de Fluidos, MEC 242 Sistemas Fluido-Mecânicos, MEC 320 Processos de Fabricação, MEC 322 Conformação Plástica, MEC 325 Processos de Fabricação por Usinagem, MEC 351 Elementos de Máquinas I, MEC 352 Elementos de Máquinas II, MEC 420 Manufatura Assistida por Computador, MEC 451 Dinâmica Veicular, MEC 494 Introdução à Análise por Elementos Finitos, MEC 495 Projeto de Engenharia Mecânica), além de projetos de pesquisa e extensão. Para que o aluno que queira solicitar o cadastro de usuário tenha acesso ao formulário, também foi elaborado um folder para ser afixado na porta do laboratório que contém o link e um QR Code para acessá-lo, conforme pode ser verificado na Figura 3.

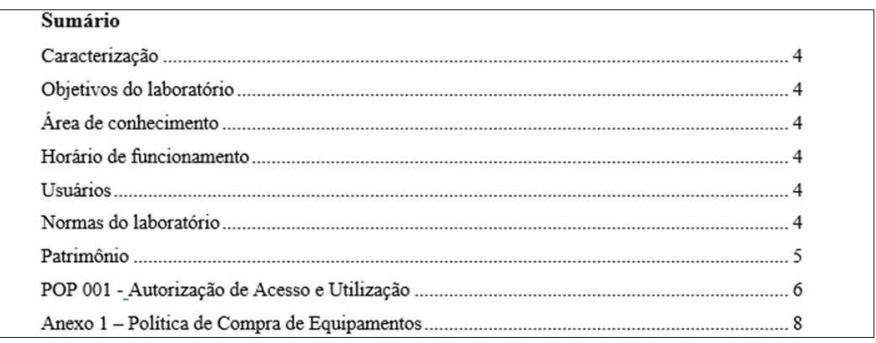

Figura 2 - Sumário do Manual de Normas e Procedimento do Laboratório de CAM.

\section{Solicite seu cadastro de usuário! \\ Acesse o formulário por meio da leitura do $Q R$ code ou ainda pelo link: https://goo.gl/ojqqEq

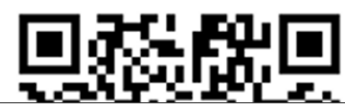

Figura 3 - Excerto do folder que dá orientações para acessar o formulário.

A Figura 4 apresenta o detalhe do procedimento operacional padrão "Autorização de acesso e utilização". Observa-se nesta figura que os passos para a utilização do laboratório são dados por meio do site com a inserção de dados do solicitante com os critérios para deferir ou indeferir a solicitação de cadastro como usuário.

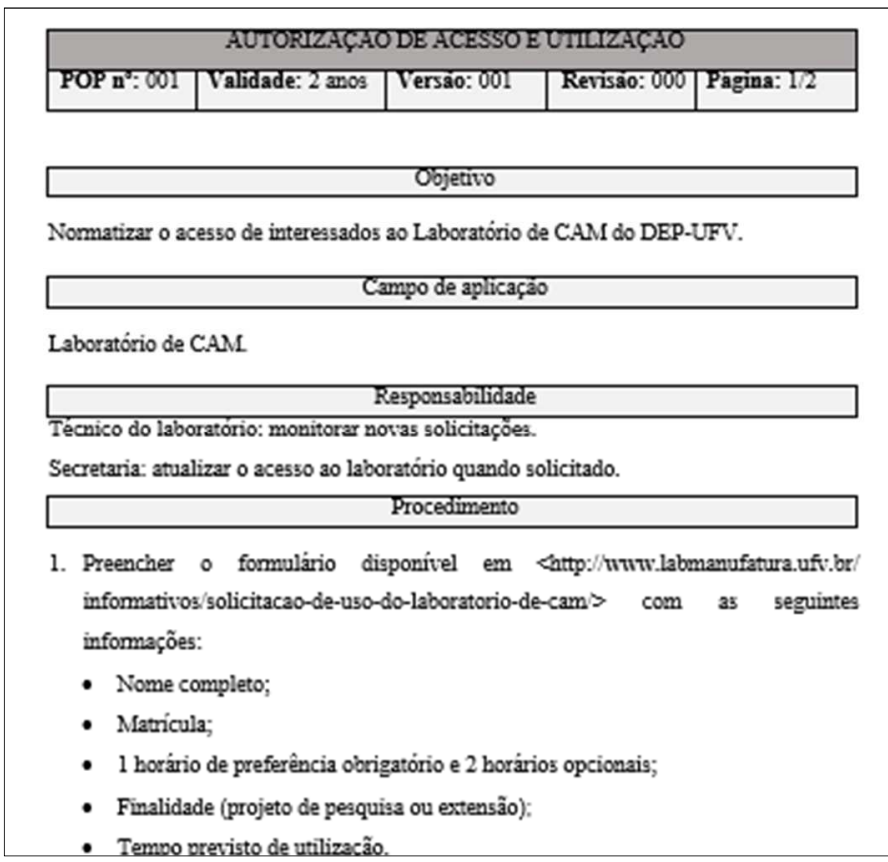

Figura 4 - Excerto do procedimento de autorização de acesso e utilização do Lab-CAM.

Laboratórios de Manufatura Assistida por Computador e de Usinagem: conforme já descrito, foi elaborado um manual conjunto para os Laboratórios Lab-CAM e Lab-USI. A justificativa para esta união vem do fato de ambos terem objetivos relacionados à usinagem, terem equipamentos 
apropriados para operações de usinagem e terem aulas práticas, portanto, similares em termos de necessidade de material, ferramenta e precauções. O sumário deste manual, que contém as normas e procedimentos de ambos, é exibido na Figura 5. Este manual foi elaborado conforme o trabalho de Lima (2014).

\begin{tabular}{|c|}
\hline $\begin{array}{l}\text { Sumário } \\
\text { Caracterização ...................... }\end{array}$ \\
\hline 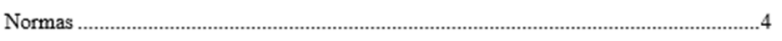 \\
\hline Do acesso, uso e prioridade ..... \\
\hline Dos equipamentos...... \\
\hline Dos materiais ........ \\
\hline 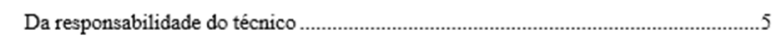 \\
\hline Da responsabilidade do coordenador .................... \\
\hline 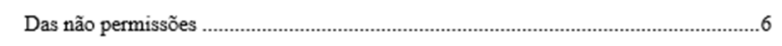 \\
\hline 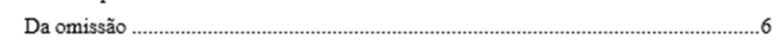 \\
\hline Laboratório de Manufatura Assistida por Computador...... \\
\hline Objetivos \\
\hline Área de concentração.................. \\
\hline Horário de funcionamento ....... \\
\hline 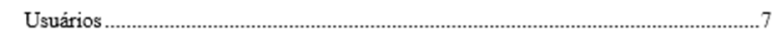 \\
\hline Patrimônio .............. \\
\hline Laboratório de Usinagem .......... \\
\hline Objetivos ................................. \\
\hline Área de concentração......... \\
\hline Horário de funcionamento ........ \\
\hline 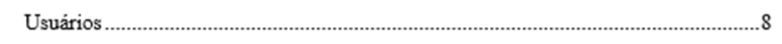 \\
\hline 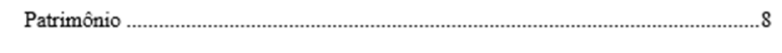 \\
\hline POP 01 - ACESSO E UTILIZAÇÃO \\
\hline POP 02 - OPERAÇÃO E LIMPEZA DA FRESA \\
\hline POP 03 - OPERAÇÃO E LIMPEZA DO TORNO \\
\hline POP 04 - OPERAÇÃO E LIMPEZA DO CENTRO DE USINAGEM....... \\
\hline
\end{tabular}

Figura 5 - Sumário do manual de normas e procedimentos do Lab-MAN e Lab-USI.

As normas elaboradas contemplam o acesso, uso e prioridade, equipamentos, materiais, responsabilidades do técnico, coordenador, não permissões e omissão. Isto se justifica pelo fato de que foram pensadas para a pesquisa, o ensino e a extensão e, como muitas vezes os recursos e materiais consumíveis vem de fontes diferentes, é fundamental para manter um padrão de decisão em caso de divergências entre interessados. Além disso, há priorização das aulas práticas de MEC 325 (Processos de Usinagem) e as demais atividades de projetos de pesquisa e extensão são alocadas em função dos horários livres que restam.

$\mathrm{O}$ procedimento operacional padrão (POP) descrito (comum aos dois laboratórios) foi o de acesso e utilização, em virtude de ambos compartilharem as normas sugeridas e, portanto, não haver necessidade de elaborar um procedimento igual à exceção do campo de aplicação. Este procedimento é exibido na Figura 6. Observa-se que o procedimento contempla o uso de equipamento de proteção individual (EPI). Como se trata de um ambiente sujeito a riscos de acidente com cavacos ou diretamente com as máquinas, é fundamental que esta norma seja mantida.

Laboratório de Manufatura: relativo exclusivamente ao Lab-MAN, foram elaborados os procedimentos de aula prática de operação de torneamento e do CNC. O excerto do procedimento da aula prática de torneamento pode ser verificado na Figura 7. Conforme o procedimento, é preciso que o técnico do laboratório defina a aula juntamente com o professor 1 dia antes da aula.

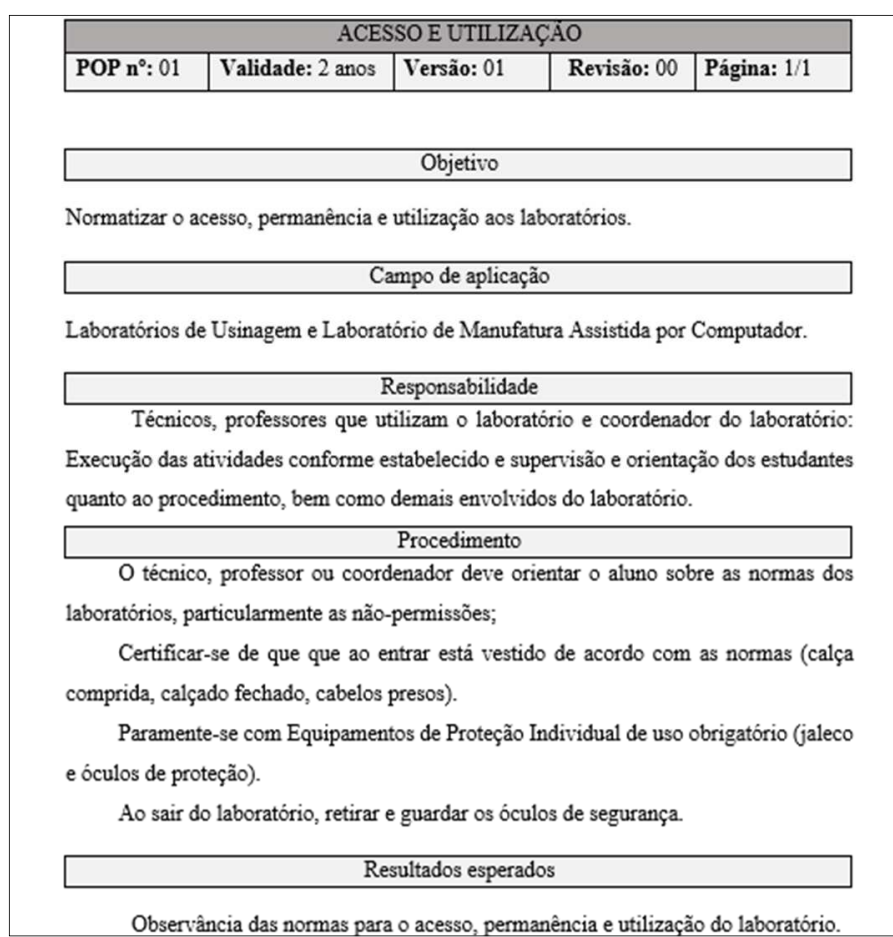

Figura 6 - Procedimento operacional padrão de acesso e utilização do Lab-MAN e Lab-USI.

Procedimento
1. O técnico deve definir juntamente com o professor responsável pela aula prática um
dia antes da mesma o processo a ser demonstrado. O professor deve fornecer as
condições de corte para o material selecionado de acordo com o processo de usinagem
e as operações.
2. Preparação do material a ser usinado. É responsabilidade do DEP fornecê-1o. Em casos de operações de usinagem em componentes específicos de projetos de pesquisa ou extensão, o professor orientador do projeto deverá fornecer o material do componente.

3. Preparar o ferramental (juntamente com o porta-ferramentas) necessário para as operações de usinagem.

4. Preparar o dispositivo de fixação da peça na máquina ferramenta (setup):

4.1. Energizar a máquina-ferramenta;

4.2. Fixar a peça de trabalho na placa de castanhas;

4.3. Realizar o furo de centro;

Figura 7 - Excerto do procedimento operacional padrão de aula prática de operação de torneamento.

Com o acesso ao POP, o aluno tem consciência de que o setup foi elaborado cuidadosamente pelo técnico. Foi elaborado também o procedimento para a aula prática de demonstração de operação da máquina $\mathrm{CNC}$, que pode ser verificado na Figura 8. A elaboração do POP para as aulas é importante para o professor, técnico e os alunos. Este documento contribui para o entendimento das atividades desenvolvidas e preza pela segurança dos usuários. Além disso, já prepara o aluno para uma situação real de processo de fabricação na indústria.

O POP colabora também para a preparação da aula prática, deixando tudo mais fluido na execução da mesma. No caso de processos de usinagem, deve-se ter preparado os corpos de prova, ferramentas, dispositivos de fixação, condições de corte para cada operação executada na aula prática. A padronização contribuirá para que a seleção de todas as variáveis ocorra da forma otimizada. Na Figura 9 encontra-se um excerto do procedimento da aula prática de operação de fresamento. 
OPERAÇÃO E LIMPEZA DO CENTRO DE USINAGEM \begin{tabular}{|l|l|l|l|l|}
\hline POP n $^{\circ}: 04$ & Validade: 2 anos & Versão: 01 & Revisão: 00 & Página: $1 / 2$ \\
\hline
\end{tabular}

\section{Objetivo}

Normatizar a operação do centro de usinagem e sua limpeza.

\section{Campo de aplicação}

Laboratório de Manufatura Assistida por Computador.

Responsabilidade

Técnico do laboratório: operar o equipamento;

Professor: ministrar e supervisionar a aula.

\begin{tabular}{ll|}
\hline \multicolumn{1}{|c|}{ Materiais necessários } \\
\hline - Tarugo; \\
- Ferramenta. \\
\hline \multicolumn{1}{|c|}{ Procedimento } \\
\hline 1. O técnico deve definir juntamente com o professor responsável pela aula prática \\
$\quad$ um dia antes da mesma o processo a ser demonstrado. O professor deve fornecer
\end{tabular}

Figura 8 - Excerto do procedimento operacional padrão da aula prática de operação do CNC.

\begin{tabular}{l} 
Procedimento \\
\hline 1. O técnico deve definir juntamente com o professor responsável pela aula prática um \\
dia antes da mesma o processo a ser demonstrado. O professor deve formecer as \\
condições de corte para o material selecionado de acordo com o processo de usinagem \\
e as operações.
\end{tabular}

2. Preparação do material a ser uainado. E responsabilidade do DEP formecê-lo. Em casos de operações de usinagem em componentes especificos de projetos de pesquisa ou extensão, o professor orientador do projeto deverá fomecer o material do componente.

3. Preparar o ferramental (juntamente com o porta-ferramentas) necesgário para as operações de usinagem.

4. Preparar o dispositivo de fixação da peça na máquina ferramenta (setup):

4.1. Energizar a máquina-ferramenta

4.2. Fixar a peça de trabalho na mesa de trabalho

4.3. Coletar o zero peça

5. Definição das condiçōes de usinagem: ligar a rotação do eixo arvore (rotação é dependente da velocidade de corte), selecionar o avanço da ferramenta, definir a profundidade de corte.

6. Efetuar a operação de usinagem.

7. Aferição dos parâmetros verticais de rugosidade, quando necessário.

8. Esclarecimentos de eventuais dúvidas sobre o processo e operação em questão

9. Repetir as etapas de 5 a 8 (se necessário).

10. Limpeza da máquina-ferramenta: retira-se a peça usinada da área de trabalho da máquina-ferramenta, efetua-se a limpeza da máquina-ferramenta.

11. Manutenção da máquina-ferramenta: efecua-se a lubrificação da máquina-ferramenta

Figura 9 - Excerto do Procedimento operacional padrão da aula prática de operação de fresamento.

\subsection{Procedimentos analíticos e gerenciais}

Para entender o contexto no qual os laboratórios estão inseridos, foi elaborado o organograma funcional do DEP. A elaboração foi baseada na estrutura previamente disponibilizada pelo próprio departamento e também em entrevistas com professores. Como o contexto interno do DEP-UFV não é sujeito a grandes mudanças, o organograma funcional foi considerado o mais adequado para ser elaborado. Verifica-se na Figura 10 sua representação.

O organograma é uma ferramenta fundamental. Com ele, a compreensão das relações de trabalho e da estrutura interna da organização é facilitada. Conforme Howes (2011), essa estrutura também permite que os conhecimentos sejam reunidos, e assim, cria-se a oportunidade de aprofundá-los.

Planilha de controle de estoque: para o Lab-MAN foi elaborada uma planilha eletrônica para controle de estoque. Foram utilizados dados históricos desde o ano de 2014. O objetivo é auxiliar o coordenador do laboratório a saber quando é preciso comprar materiais e ferramentas novamente e fazer a previsão orçamentária junto ao Departamento de maneira adequada. A captura de tela desta planilha pode ser verificada na Figura 11

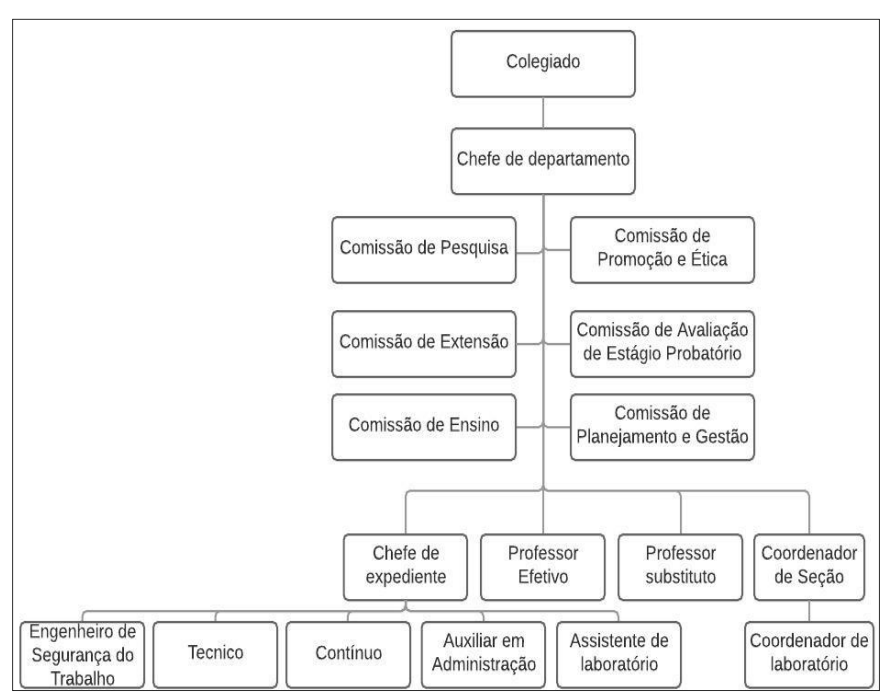

Figura 10 - Organograma do DEP.

Durante o levantamento deste procedimento constatou que havia material para atividades de ensino para um período de 15 anos, já para demais pesquisa ou extensão há falta de material. A constatação e análise desta situação permite ao gestor uma otimização de recursos financeiros e dosagem adequada de material de consumo para atender ensino, pesquisa e extensão.

Política de compra: Com o levantamento das políticas de duas instituições: Instituto Federal de Santa Catarina (IFSC) e Secretaria de Estado de Infraestrutura e Logística do Mato Grosso (SINFRA-MT), foi elaborada uma política para a requisição de novos equipamentos para o Lab-CAM. A vida útil encontrada, as instituições e os equipamentos podem ser verificados na Tabela 4 . A proposta desta política de compras encontra-se na Figura 12.

A vida útil proposta dos computadores de mesa foi estipulada em 4 anos pois o laboratório demanda equipamentos com boa capacidade de processamento em virtude dos programas que os computadores devem suportar e, portanto, o uso por mais 1 ano pode ser antieconômico e não-vantajoso.

Website: conforme Balioni e Ribeiro (2009), a divulgação da produção científica é fundamental para que as publicações dos pesquisadores atinjam diferentes públicos. Assim, como meio de comunicação permanente entre professores, estudantes e a comunidade universitária, foi solicitado pela pesquisa para a Diretória de Tecnologia da Informação da UFV (DTI-UFV), o desenvolvimento de um website. 


\begin{tabular}{|c|c|c|c|c|c|c|}
\hline \multicolumn{7}{|c|}{ Controle de estoque } \\
\hline Item & $\begin{array}{c}\text { Inventário } \\
\text { inicial } \\
\text { (unidades) }\end{array}$ & Matéria & $\begin{array}{l}\text { Estimativa de } \\
\text { duração (anos) }\end{array}$ & $\begin{array}{c}\text { Zero } \\
\text { estoque } \\
\text { em }\end{array}$ & $\begin{array}{c}\text { Quando } \\
\text { comprar } \\
\text { novamente }\end{array}$ & $\begin{array}{c}\text { Estimativa duração } \\
\text { do processo } \\
\text { licitatório (dias) }\end{array}$ \\
\hline Inserto de 6 arestas & 1 & MEC 325 & 10,0 & $25 / 08 / 2028$ & $25 / 08 / 2028$ & \\
\hline Bedame & 1 & MEC 325 & 1,5 & $25 / 02 / 2020$ & $25 / 02 / 2020$ & \\
\hline Tarugo 5 " diâmetro por $350 \mathrm{~mm}$ e comprimento & 15 & MEC 325 & 1,0 & $25 / 08 / 2033$ & $25 / 08 / 2033$ & \\
\hline
\end{tabular}

Figura 11 - Excerto da planilha de controle de estoque.

Tabela 4 - Vida útil máxima de equipamentos de tecnologia de informação.

\begin{tabular}{|c|c|c|c|c|}
\hline Instituição & $\begin{array}{c}\text { Computadores de } \\
\text { mesa }\end{array}$ & Monitores & $\begin{array}{c}\text { Mouse e } \\
\text { teclado }\end{array}$ & $\begin{array}{l}\text { Peças de } \\
\text { reposição }\end{array}$ \\
\hline Instituto Federal de Santa Catarina (ISFC) & 5 & 4 & - & - \\
\hline $\begin{array}{l}\text { Secretaria de Estado de Infraestrutura e Logística do } \\
\text { Mato Grosso (SINFRA-MT) }\end{array}$ & \multicolumn{4}{|c|}{4} \\
\hline
\end{tabular}

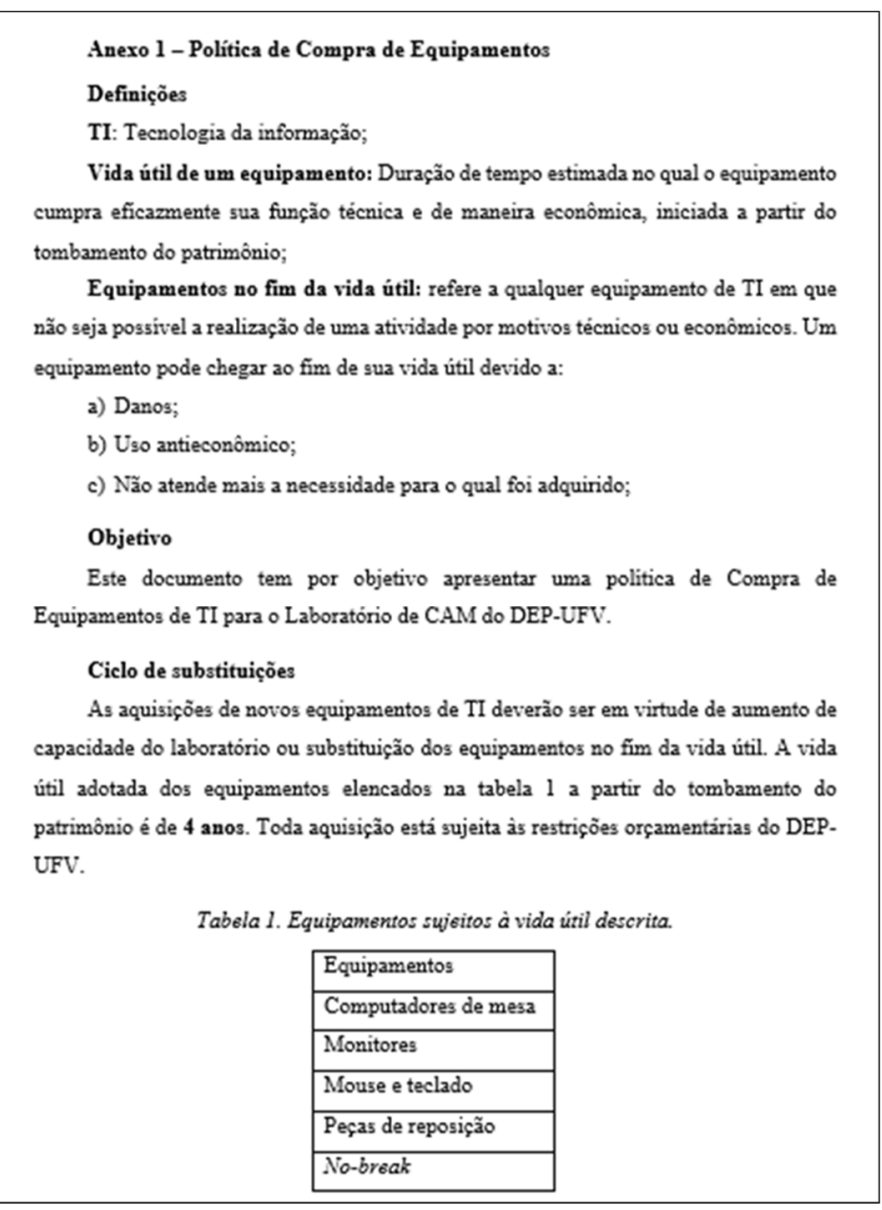

Figura 12 - Política de Compras de Equipamentos para o Lab-CAM.

Este foi solicitado com o objetivo da divulgação do laboratório e dos trabalhos acadêmicos. Neste site serão inseridas informações sobre aulas, cursos, trabalhos desenvolvidos e orientações sobre utilização do espaço. Também é uma opção para compartilhar as normas de acesso aos laboratórios e conteúdo que os professores julguem relevantes para o website e está disponível pelo link <www.labmanufatura.ufv.br> e na Figura 13 verifica-se a captura de tela da página principal do mesmo.

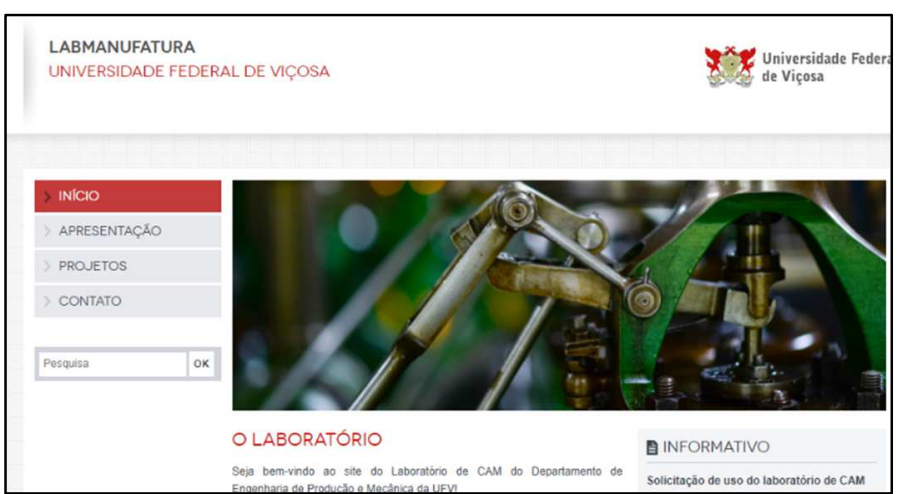

Figura 13 - Captura de tela do website do Lab-CAM.

- A bancada de granito, que a princípio deveria ser permanentemente desobstruída, não estava durante a coleta de dado deste trabalho. Contendo, por exemplo, cafeteira e itens relacionados na bancada, conforme a Figura 14(b). Ressalta-se que o laboratório se trata de um ambiente acadêmico e laboral e refeições são inadequadas dentro dele;

- O tanque de refrigeração lateral do CNC fica orientado para o corredor onde são os gabinetes dos professores, portanto, seria mais adequado haver uma parede, conforme o projeto original, para obstruir o ruído proveniente da máquina, conforme pode ser visto na Figura 14(c). Além do fato de que, conforme Bortoluzzi (2011), este equipamento é indicado para ser utilizado em ambientes que dispõem de controle térmico por causa de seus componentes eletrônicos e a precisão, questão não observada no laboratório;

- Relativo ao torno mecânico convencional, sua disposição paralela é inadequada de acordo com Bortoluzzi (2011). Isto se deve ao fato de que deve ser posicionado em diagonal em virtude da maior área de trabalho e acesso para o operador devido à movimentação frequente necessária para ajustar o equipamento; 

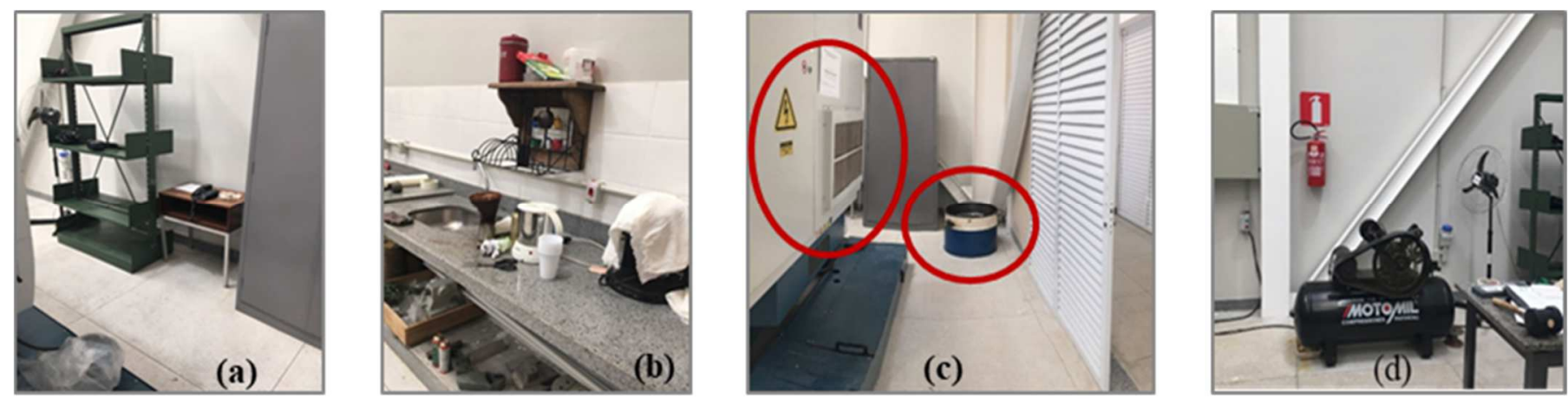

Figura 14 - (a) Telefone do Lab-MAN; (b) Tanque de refrigeração do CNC, obstrução à circulação e porta para o corredor dos gabinetes; (c) Cafeteira na bancada de granito do laboratório; (d) Compressor de ar.

- De acordo com Villar e Júnior (2014), a dimensão para passagens internas industriais para pessoas é de $0,9 \mathrm{~m}$. Foi utilizado esta dimensão como parâmetro para avaliar a circulação do laboratório. Como o corredor de passagem ao lado do CNC é o de maior circulação e é 1,4 $\mathrm{m}$, a dimensão para circulação está adequada, no entanto, foi observado que uma das passagens laterais do $\mathrm{CNC}$ estava obstruída (Figura 14(c));

- O laboratório possui um compressor de ar por não ter uma rede de ar comprimido (Figura 14 (d)). Isso é crítico para o laboratório, visto que quando o $\mathrm{CNC}$ estiver em operação, o ruído no laboratório será proveniente tanto da máquina operando quanto do compressor de ar. Tal fato representa uma dificuldade para serem conduzidas aulas paralelas nos demais laboratórios, além do ruído ser consideravelmente alto na instalação do LABENGE como um todo.

De acordo com Peinado e Graeml (2007), a elaboração de um bom arranjo físico também requer o levantamento da necessidade da área física. Assim, elencam os seguintes conceitos que devem ser considerados no cálculo da necessidade da área conforme foi apresentado na Tabela 2 e cuja adaptação necessária para aplicação na pesquisa podem ser verificados na Tabela 3. O cálculo das áreas realizado encontra-se na Tabela 5.

De acordo com Peinado e Graeml (2007), a elaboração de um bom arranjo físico também requer o levantamento da necessidade da área física. Assim, elencam os seguintes conceitos que devem ser considerados no cálculo da necessidade da área conforme foi apresentado na Tabela 2 e cuja adaptação necessária para aplicação na pesquisa podem ser verificados na Tabela 3.

O cálculo das áreas realizado encontra-se na Tabela 5.
Ressalta-se que se usou $2 \mathrm{~m}$ como dimensão da aresta não viva para o cálculo da superfície de operação do CNC conforme recomendação de Peinado e Graeml (2007). Assim, na disposição do arranjo físico, as áreas ficariam projetadas da maneira demonstrada na Figura 15.

\subsection{Discussão}

É importante que haja um site para os laboratórios do LABENGE. Espera-se que a elaboração do website dos laboratórios contribua para difusão do conhecimento e acesso à informação para alunos, servidores e comunidade em geral e, assim, contribua para que o departamento e a universidade como um todo ganhe visibilidade na área de fabricação. Com as informações sobre normas e procedimentos dos laboratórios, espera-se que haja benefícios para as diversas pessoas pertinentes a eles: chefia, coordenadores, professores, técnicos, alunos e demais interessados. Com a publicidade dessas informações, há economia de tempo por parte de quem precisa encontrar informações e não precisa mais consultar uma outra pessoa para conseguir a informação.

Além disso, com a delegação e priorização de atividades e normas que discorrem sobre equipamentos, materiais e outras questões, eventuais pontos de discordância e dúvidas podem ser consultados para se encontrar a solução buscada. Assim, as pessoas envolvidas no procedimento sabem o que, quando e como executar e, consequentemente, há melhor condução das operações e harmonização das atividades. Por causa disso, não há pretensão de se realocar os equipamentos conforme o perfil de usuário, e uma vez que não foi feita essa distinção, também não foi feita a classificação da vida útil remanescente.

\section{Tabela 5 - Cálculo de áreas do Lab-Man.}

Tabela 5 - Cálculo de áreas do Lab-Man.
\begin{tabular}{l|l|l}
\hline \multicolumn{1}{c}{ Conceito } & \multicolumn{2}{l}{ ANC Área projetada } \\
Aresta viva & 1 lado & 1 lado \\
\hline Sp & $2,60 \mathrm{~m} \times 2,85 \mathrm{~m}=7,41 \mathrm{~m}^{2}$ & $1,20 \mathrm{~m} \times 3,00 \mathrm{~m}=3,60 \mathrm{~m}^{2}$ \\
\hline So & $\begin{array}{l}2,60 \mathrm{~m} \times(2,00 \mathrm{~m} \times(50 \%))=2,60 \mathrm{~m} \times 1,00 \\
\mathrm{~m}=2,60 \mathrm{~m}^{2}\end{array}$ & $3,00 \mathrm{~m} \times(1,20 \mathrm{~m} \times(50 \%))=3,00 \mathrm{~m} \times 0,60 \mathrm{~m}=2,10 \mathrm{~m}^{2}$ \\
\hline Sc & $\left(7,41 \mathrm{~m}^{2}+2,60 \mathrm{~m}^{2}\right) / 2=5,00 \mathrm{~m}^{2}$ & $\left(3,60 \mathrm{~m}^{2}+2,10 \mathrm{~m}^{2}\right) / 2=2,85 \mathrm{~m}^{2}$ \\
\hline
\end{tabular}




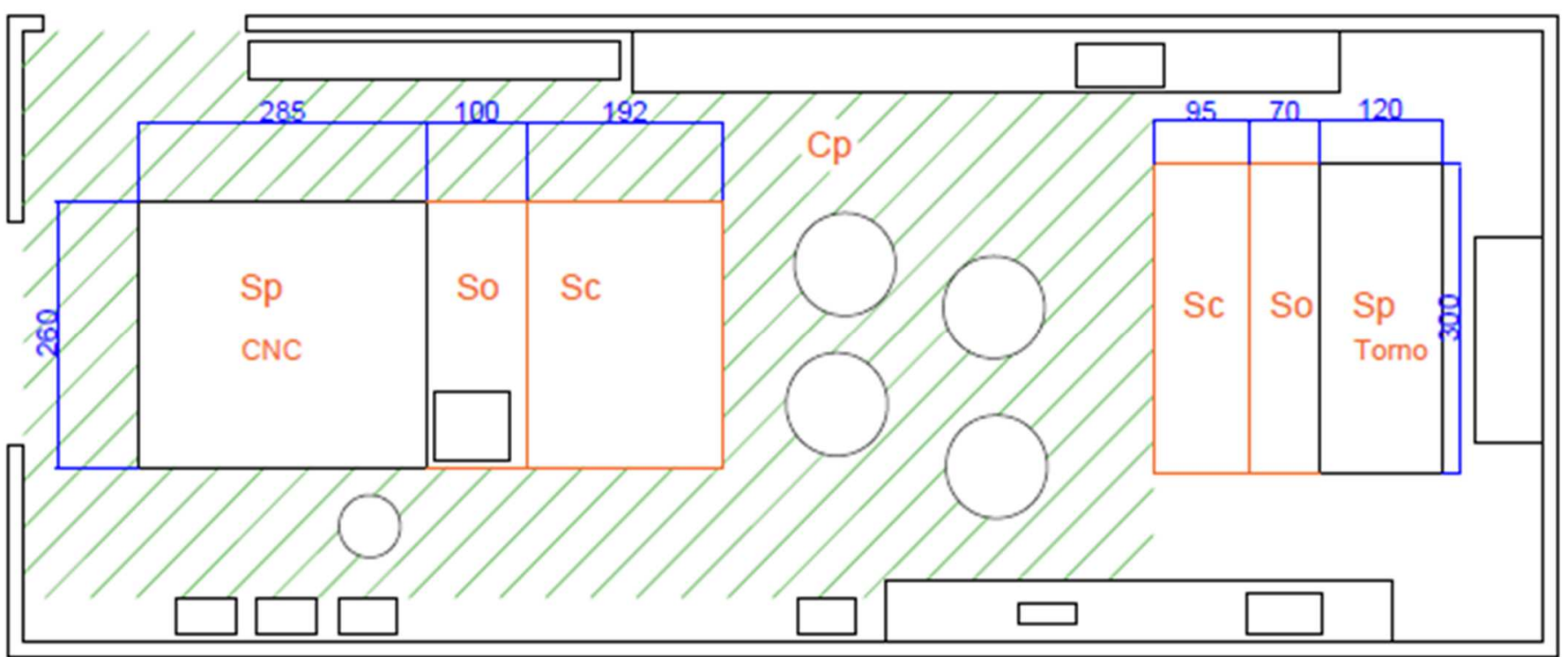

Figura 15 - Representação das áreas na projeção bidimensional do Lab-MAN.

Ademais, com o manual do Lab-CAM, o coordenador do laboratório terá as atividades de gerenciamento e controle de forma otimizada pois terá registrado quem está utilizando o laboratório, quando e com que objetivo e permite, portanto, saber com precisão a demanda dos projetos e alunos quanto à utilização dos equipamentos, além de manter o registro patrimonial do laboratório.

Lab-MAN: notou-se que há diversos pontos de melhoria no Lab-MAN. As análises feitas sobre o leiaute implicam em pontos de melhoria como: desobstrução de espaços, realocação de torno, instalação de rede de ar comprimido, entre outros. A implementação da sugestão de instalação de rede de ar comprimido, depende de planejamento orçamentário e de projeto, de forma que seria necessário um estudo para avaliar o impacto e custo antes de realizar a sugestão propriamente. No geral, as sugestões variam em exequibilidade e custo, e, portanto, uma análise individual de cada uma é necessária caso seja decidido implementá-las. É interessante destacar que as áreas calculadas fossem demarcadas no chão. Isto facilita o operador da máquina executar os processos durante as aulas e sinalizar os alunos permaneçam dentro da superfície de circulação durante as aulas. No entanto, essa superfície seria mais adequada se fosse uniforme tanto para o torno quanto para o CNC em virtude da quantidade de alunos que não varia independente de qual máquina será utilizada

Além disso, espera-se que com a planilha desenvolvida para a previsão de demanda, o Lab-MAN e o Lab-USI sejam capazes de, por meio da quantidade de aulas planejadas ao longo do semestre, estimar a necessidade de ferramentas e consumíveis e, portanto, saber previamente o que, quando, quanto e a que custo adquirir. Considerando-se que a disponibilidade de recursos financeiros é limitada, é evidente a necessidade de otimizar sua utilização.

\section{CONCLUSÕES}

Foram feitos o estudo de leiaute do Lab-MAN, redação do manual de procedimentos analíticos e operacionais padrão dos laboratórios e website para conjuntamente, formarem o plano de gerenciamento dos Laboratório de Manufatura, de CAM e de Usinagem do DEP. Com isto, conclui-se que:
- A elaboração de um plano de gerenciamento para uma organização é fundamental para a tomada de decisões que impactarão a curto, médio e longo prazo;

- O arranjo físico é fundamental para o bom funcionamento do laboratório. Um leiaute bem projetado apresenta como benefício o aumento da moral e satisfação no trabalho, melhor fluxo do processo, disposição racional dos elementos físicos e maior segurança no ambiente de trabalho;

- O controle e gerenciamento de estoque dos laboratórios afeta direta diretamente o orçamento do DEP. Com a gestão de estoques é possível atender melhor o ensino, a pesquisa e a extensão;

- Os procedimentos operacionais padrão são cruciais. Eles são pontos chaves na realização de operações de maneira padronizada, para a manutenção do conhecimento e garantia de qualidade não somente nos laboratórios, mas como em qualquer organização.

Sugere-se que em pesquisas futuras, seja contemplado também o Laboratório de Metrologia do LABENGE-UFV, bem como seja feita a proposição de um novo leiaute do Laboratório de Manufatura baseado nas análises da presente pesquisa.

\section{REFER Ê N C I A S}

BORTOLUZZI, A. C. Implantação de um laboratório de usinagem em uma instituição de ensino através do estudo de leiaute - um estudo de caso. 2011, 50 f. Monografia (Pós-Graduação em Engenharia e Segurança do Trabalho) - Universidade do Oeste De Santa Catarina, SC, 2011.

RODRIGUES, et al. Normas de Segurança e Conduta nos Laboratório de Ensino da Área Acadêmica de Engenharia. 2012. Disponível em: <https://www.formiga.ifmg.edu.br/documents/2016/Lab oratoriosdeEnsino/NormasLaboratoriosdeMaquinasElet ricasAutomacaoCircuitoseEletronica.pdf >. Acesso em: 23 setembro de 2018.

SILVA, A. C. Evolução da administração pública no Brasil e tendências de novos modelos organizacionais, 2015. Disponível

em: <http://www.ice.edu.br/TNX/storage/webdisco/2013/12 
/13/outros/27b4d512efbac7d37520bc37aa78cac1.pdf>. Acesso em 25 setembro de 2018.

KOHL, A.; OLIVEIRA, J. N. D. Gestão da Qualidade na Administração Pública Brasileira. 2017. Disponível em: <www.inovarse.org/sites/default/files/T12_0455_2744. pd>. Acesso em 25 de agosto de 2017.

ABCM. Journal of the Brazilian Society of Engineering and Mechanical Sciences. 2004. Disponível em: http://www.abcm.org.br/journal/index.shtml. Acesso em 1 de fereveiro de 2018.

BORDALO, S. N.; FERZIGER, J. H.; KLINE, S. J. The Development of Zonal Models for Turbulence, Proceedings of the 10th Brazilian Congress of Materials Engineering. Rio de Janeiro: ABM, v.2, p. 41-44, jun. 1989.

CAMPOS, V. F. Gerenciamento da rotina do trabalho do dia-adia. 2. ed. Nova Lima/MG: INDG, 1994.

CAMPOS, V. F. Qualidade total: Padronização de empresas. $4^{\text {a }}$ ed. Belo Horizonte: Fundação Christiano Ottoni, 1992. $124 \mathrm{p}$.

CHIAVENATO, I. Administração de materiais: uma abordagem introdutória. Rio de Janeiro: Elsevier, 2005.

COIMBRA, A. L. Usinabilidade dos metais. 3 ed. São Paulo: Edgard Blücher, 1999, 234 p.

DEMING, W. E. Qualidade: A Revolução da Administração, Rio de Janeiro: Marques Saraiva, 1990.

ERDMANN, R. H. Gestão da qualidade no setor público. 2011, 116 f. Florianópolis, Departamento de Ciências da Administração da UFSC. 2011.

FERREIRA, J. R.; GOMES, J. C. Gerenciamento de Laboratórios de Análises Químicas, Fundação Arthur Bernardes. Viçosa, 1995.

HOWES, B. H. G. D. Proposta de Transformação do Núcleo de Pesquisas da Fecomércio SC em um Instituto de Pesquisa Estratégico para Santa Catarina. 2011, 115 f. Monografia (Graduação em Administração) - Universidade Federal de Santa Catarina, SC, 2011.

INSTITUTO FEDERAL DE SANTA CATARINA. Instrução
Normativa 04/2015. 2015. 2017. Disponível em: $<$ http://dtic.ifsc.edu.br/files/IN-04-

2015_desfazimento_bens_TI.pdf>. Acesso em 19 outubro de 2018.

LIMA, D. B; GARCIA, R. N. Uma investigação sobre a importância das aulas práticas de Biologia no Ensino Médio, Cadernos do Aplicação, Porto Alegre, v. 24, n. 1, p. 201-224, 2011.

LIMA, L. M. (Coord.). Normas e Rotinas Operacionais: Laboratório de Bioquímica. Viçosa, 2014.

MATO GROSSO (Estado). Secretaria de Estado de Infraestrutura e Logística. Política de Gestão de Obsolescência de Equipamentos de TI da Secretaria de Estado de Infraestrutura e Logística - SINFRA. Cuiabá, 2017. 16p.

PEINADO, J.; GRAEML, A. R. Administração da produção: operações industriais e de serviços. Curitiba: UnicenP, 2007.

SIMPÓSIO DE INICIAÇÃO CIENTÍFICA DA UNIVERSIDADE FEDERAL DO ABC. Elaboração de um site para divulgação do conhecimento acadêmico e científico produzido na UFABC (Resumo). Santo André, SP: Universidade Federal do ABC, 2009. 3p.

SLACK, N.; CHAMBERS, S.; JOHNSTON, R. Administração da Produção. $3^{\text {a }}$ ed. São Paulo: Atlas, 2009.728 p.

VILLAR, A. M.; NOBREGA JÚNIOR, C. L. Planejamento das Instalações Industriais. João Pessoa: Editora da UFPB. 2014. 279 p.

WERKEMA, M. C. C. Ferramentas estatísticas básicas para o gerenciamento de processos. Belo Horizonte: Fundação Christiano Ottoni, 1995. 290 p.

ZONTA JUNIOR, A.; BOEHS, L.; CASTRO, P. R. A. Planejamento Técnico no Gerenciamento de Ferramentas - Estudos de caso em empresas do setor metalmecânico brasileiro. In: V - CONEM - Congresso Nacional de Engenharia Mecânica. Salvador, 2008. 